\title{
Article \\ E-Learning Development Based on Internet of Things and Blockchain Technology during COVID-19 Pandemic
}

\author{
Amir Masoud Rahmani ${ }^{1,+}{ }^{,}$Rizwan Ali Naqvi ${ }^{2,+} \mathbb{D}$, Mazhar Hussain Malik ${ }^{3}$, Tauqeer Safdar Malik ${ }^{4}$ (D), \\ Mahyar Sadrishojaei ${ }^{5}$, Mehdi Hosseinzadeh ${ }^{6, *(\mathbb{D})}$ and Ali Al-Musawi ${ }^{7, *(D)}$
}

1 Future Technology Research Center, National Yunlin University of Science and Technology, Douliou, Yunlin 64002, Taiwan; rahmania@yuntech.edu.tw

2 Department of Intelligent Mechatronics Engineering, Sejong University, Seoul 05006, Korea; rizwanali@sejong.ac.kr

3 Department of Computing, Global College of Engineering and Technology, Muscat 112, Oman; mazhar@gcet.edu.om

4 Department of Computer Science, Air University Multan Campus, Multan 60000, Pakistan; tauqeer.safdar@aumc.edu.pk

5 Department of Industry, University of Applied Science and Technology (UAST), Tehran 11369, Iran; mahyar_sadri@uast.ac.ir

6 Pattern Recognition and Machine Learning Lab, Gachon University, 1342 Seongnamdaero, Sujeonggu, Seongnam 13120, Korea

7 Education Technology, Sultan Qaboos University, Muscat 112, Oman

* Correspondence: mehdi@gachon.ac.kr (M.H.); asmusawi@squ.edu.om (A.A.-M.)

+ Amir Masoud Rahmani and Rizwan Ali Naqvi have contributed equally to this work.

Citation: Rahmani, A.M.; Ali Naqvi, R.; Hussain Malik, M.; Malik, T.S.; Sadrishojaei, M.; Hosseinzadeh, M.; Al-Musawi, A. E-Learning Development Based on Internet of Things and Blockchain Technology during COVID-19 Pandemic. Mathematics 2021, 9, 3151. https:// doi.org/10.3390/math9243151

Academic Editor: Jan Lansky

Received: 22 October 2021

Accepted: 3 December 2021

Published: 7 December 2021

Publisher's Note: MDPI stays neutral with regard to jurisdictional claims in published maps and institutional affiliations.

Copyright: (C) 2021 by the authors. Licensee MDPI, Basel, Switzerland. This article is an open access article distributed under the terms and conditions of the Creative Commons Attribution (CC BY) license (https:// creativecommons.org/licenses/by/ $4.0 /)$.
Abstract: The suspension of institutions around the world in early 2020 due to the COVID-19 virus did not stop the learning process. E-learning concepts and digital technologies enable students to learn from a safe distance while continuing their educational pursuits. Currently, the Internet of Things (IoT) is one of the most rapidly increasing technologies in today's digital world; and e-learning is one of the most powerful learning methods available. In today's world, smart devices and new technologies assist teachers in concentrating on new models of student learning while avoiding time wastage. By examining the characteristics of the Internet of Things and the challenges that exist in the field of e-learning, the potential functions, benefits, and advancements of utilizing the Internet of Things in online education are identified and discussed. This article examines the existing and future condition of the Internet of Things world as it pertains to the topic of education and sophisticated capabilities available through the Internet of Things that enable the application of e-learning after an architecture has been designed. Students' pulse rates, brain waves, and skin resistance are measured in real time by a collection of IoT sensors, including cameras, microphones, and wearable gadgets. By utilizing the proposed architecture, universities can change their distance learning tactics to maximize resources and boost efficiency without changing their overall academic activities. According to the study's findings, e-learning has a favorable and statistically significant impact on students' flexibility, learning experience, educational productivity, and overall quality of education.

Keywords: Internet of Things; COVID-19; e-learning; blockchain; IoT-based e-learning

\section{Introduction}

The World Health Organization has identified COVID-19 as a global epidemic with adverse consequences in many parts of society [1,2]. Despite the tragic events of COVID-19, the exceptional circumstances created a new platform that led to the development of elearning and digital education [3]. The disease outbreak has halted educational processes at the graduate level, leading to poor exam results and negatively impacting students' future employment. Update models were implemented for educational systems in countries [4]. 
As a result of the rapid expansion of new educational technologies over the past few years and the emergence of a revolution in this field, new technologies have emerged as one of the most important and memorable components of the educational process [5]. When it comes to designing teaching methods and learning outcomes, these technologies have a lot of potential [6]. On the other hand, e-learning uses modern technology to access educational programs available on the Internet [7]. E-learning is no longer restricted to online lectures, virtual classes, and pre-prepared content due to the rapid rise of information and communication technologies. The arrival of the Internet of Things (IoT) has impacted earlier models of e-learning, transforming it into a more participatory and appealing approach [8]. In all regions of the world, the IoT communication paradigm is changing students' learning processes and creating an ecosystem that accelerates interaction between teachers and students.

The IoT is a large platform comprised of an array of things containing electronics, computers, sensors, and networking elements that allow for a high degree of satisfaction in integrating necessary services around the world [9]. This is accomplished by constantly interchanging data between producers, consumers, and other computing devices [10]. Everything in the IoT communicates with other things through the Internet infrastructure, making the IoT a worldwide distributed system [11]. Everything has an Internet Protocol (IP) address in the IoT that can communicate and interact with any other object, both virtually and physically [12]. The IoT's primary goal is to connect everything on the planet to provide complete global access to the Internet. According to Gartner, by the end of 2021, around 25 billion gadgets will be connected through the IoT [10]. The many IoT-based devices determine the strength and superiority of this platform that it supports.

Following Figure 1, principles in the IoT world are commonly applied in many areas such as healthcare systems, transportation, innovative learning, manufacturers, and so on [13]. There are numerous advantages to connecting the IoT with educational approaches [14]. The IoT encourages e-learning. The majority of universities will adopt this technology to boost e-learning and education during the next few years [15]. More virtual institutions will be established, with e-learning and the advancement of modern knowledge supported by the IoT [16].

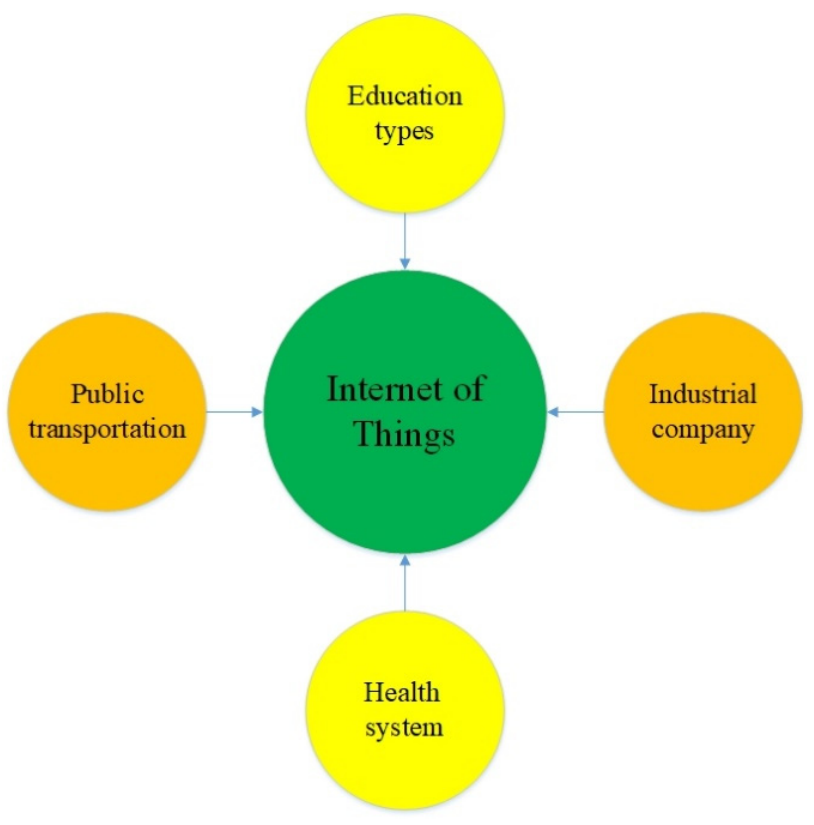

Figure 1. The most widely used IoT fields.

With this study, we hope to assist universities, and educational institutions to increase scientific knowledge in e-learning, which is the main objective. In addition, the study enables academic institutions to rethink their distant learning tactics to minimize resources 
and expenses while simultaneously increasing effectiveness without compromising the quality of their learning and teaching models. This article discusses the role of the IoT as the primary tool for e-learning at the graduate level. An IoT platform for educational processes is proposed by automatically tracking student activities and behaviors:

- Providing a practical framework for IoT-based e-learning;

- Determining the impact of the IoT on e-learning systems;

- Evaluating the performance of the IoT-based education process through a questionnaire.

The rest of the article is organized as follows: related work to e-learning is reviewed in Section 2. The potential of the IoT as a robust framework for e-learning in undergraduate and graduate education is described in Section 3. the results and benefits of using IoT are analyzed in Section 4. Finally, conclusions and suggestions for future work are given in the final section.

\section{Literature Review}

Yang and Yu [17] have described a ZigBee/GPRS wireless network technology system, sensor technology, embedded technology, web-distributed software technology, and database technology. This method uses three interconnected networks and connects several test terminals, servers, and clients, which promote the rapid flow of information and facilitate the actual implementation of distance learning. Teaching results indicate that the IoT can improve students' educational performance and teachers' teaching models. Therefore, a hot spot is considered in modern educational systems, which should be paid special attention to.

Moreover, Vharkute and Wagh [18] have designed a standard distance learning structure that combines different e-learning applications with the help of the IoT. Student satisfaction increases due to this technology-based approach, which improves the relationship between the student and the teacher while providing a cost-effective education. This training system uses GSM and GPS technology to deliver a suitable and optimal training model. Students will benefit from adopting this strategy in school buses with computer learning facilities since it will help them succeed. Lack of attention to quality is a significant weakness of this method.

Furthermore, Cornel [19] has presented an IoT-based methodology for establishing online virtual labs, a fundamental prerequisite for any education system to be high-quality and competitive in the global marketplace. This model demonstrates that practical lessons may be conducted using a remote system. Students can now take advantage of IoT capabilities to access the resources they need for various real-world investigations. As a result of this method's lower costs and higher performance of new electronic modules, it allows for the development of several web services that include data processing and communication via the Internet. By connecting an Arduino platform to the Xively web service, this technique demonstrates how to use the IoT in a practical setting. Unfortunately, this technique has low privacy.

In addition, Abbasy and Quesada [20] have suggested the most significant and expected effects of the IoT on higher education, including theoretical analysis and a statistical investigation. It examines the most important and most relevant academic and statistical outcomes of IoT in the e-learning paradigm, particularly in the context of learning and management variables. Things such as over communication, teamwork, and research opportunities distinguish this work from the rest of the field. Unfortunately, one of the shortcomings of this strategy is that it does not emphasize IoT applications in the sphere of education.

Zahedi and Dehghan [21] have discussed IoT-based e-learning in various aspects in which the main advantages of IoT in e-learning and the importance and necessity of using IoT in this regard are stated. Existing challenges and current solutions are discussed and analyzed. The results indicate that IoT will soon be a fundamental process in new technologies in e-learning, and by creating the proper infrastructure and implementing it optimally, universities will benefit significantly from IoT-based online learning models. 
Of course, the appropriate frameworks for universities wishing to adopt IoT must also be comprehensively and adequately analyzed. Implementation techniques are not considered in this method, which is regarded as one of the ambiguities and the main drawbacks of this method.

“Moreover, Ying and Jiong [22] offer the Virtual Reality-based Education eXpansion (VREX) training platform, a combination of online and offline models, to improve the curriculum and teaching experience in higher education. Virtual reality (VR) is the essential component of this platform. Aiming to enhance curriculum efficacy in an immersive environment by allowing students to have an intuitive understanding of abstract knowledge that is difficult for teachers to express, it has been used to improve the effectiveness of the curriculum in an immersive environment. The slides are converted into VR sceneries in this method, allowing students to observe and study in a real but utterly virtual environment. VREX also offers a distributed model that will enable students to participate in the interactive learning process from any location at any time. The combination of augment reality (AR) and mixed reality (MR) is not supported by this approach, which is a disappointment."

Finally, Lin and $\mathrm{Yu}$ [23] proposed a model that used wearable spherical video-based virtual reality (SVVR) and compared their design with a map guide group that used tablets to learn library functions. Both groups performed a similar test of prior knowledge, assignments, situational interest, and cognitive load. The results show that the wearable VRbased model can produce a higher degree of challenge and novelty and enhance learning and teaching. Educational systems that use SVVR have good potential to change the way students learn, improve traditional education, and increase students' understanding of content. Adoption of new technologies, the time required to complete tasks, and performance effectiveness are some of the issues not addressed in this model.

Table 1 summarizes the comparison of previous related literature in e-learning using new technologies, including the IoT.

Table 1. Comparison of previous works in the field of IoT-based e-learning.

\begin{tabular}{|c|c|c|c|c|}
\hline Mechanism & Approach & & Advantage & Weakness \\
\hline Yang and Yu [17] & $\begin{array}{l}\text { ZigBee/GPRS wireless } \\
\text { network technology } \\
\text { system for e-learning }\end{array}$ & $\checkmark$ & $\begin{array}{l}\text { Improving } \\
\text { students' } \\
\text { educational } \\
\text { performance } \\
\text { Improving } \\
\text { teachers' teaching } \\
\text { models }\end{array}$ & - $\quad$ High cost \\
\hline Vharkute and Wagh [18] & $\begin{array}{l}\text { Combines different } \\
\text { applications of } \\
\text { e-learning with the help } \\
\text { of the IoT }\end{array}$ & $\checkmark$ & $\begin{array}{l}\text { Optimal training } \\
\text { Model } \\
\text { Cost effective }\end{array}$ & - $\quad$ Low quality \\
\hline Cornel [19] & $\begin{array}{l}\text { IoT-based methodology } \\
\text { for establishing online } \\
\text { virtual labs }\end{array}$ & $\checkmark$ & $\begin{array}{l}\text { High performance } \\
\text { Low cost }\end{array}$ & - $\quad$ Low privacy \\
\hline $\begin{array}{l}\text { Abbasy and } \\
\text { Quesada [20] }\end{array}$ & $\begin{array}{l}\text { IoT on higher education, } \\
\text { including theoretical } \\
\text { analysis and a statistical } \\
\text { investigation }\end{array}$ & $\checkmark$ & $\begin{array}{l}\text { Appling technical } \\
\text { support } \\
\text { Emotional and } \\
\text { social } \\
\text { participation }\end{array}$ & $\begin{array}{l}\text { - Not emphasizing } \\
\text { IoT applications }\end{array}$ \\
\hline $\begin{array}{l}\text { Zahedi and } \\
\text { Dehghan [21] }\end{array}$ & $\begin{array}{l}\text { IoT-based e-learning in } \\
\text { various aspects }\end{array}$ & $\checkmark$ & $\begin{array}{l}\text { Proper } \\
\text { infrastructure } \\
\text { Optimal } \\
\text { implementation }\end{array}$ & $\begin{array}{l}\text { - Not considering } \\
\text { the } \\
\text { implementation } \\
\text { techniques }\end{array}$ \\
\hline
\end{tabular}


Table 1. Cont.

\begin{tabular}{|c|c|c|c|c|}
\hline Mechanism & Approach & & Advantage & Weakness \\
\hline Ying, Jiong [22] & $\begin{array}{l}\text { Virtual Reality-based } \\
\text { Education eXpansion } \\
\text { training platform }\end{array}$ & $\frac{v}{v}$ & $\begin{array}{l}\text { Better recall } \\
\text { Improve the } \\
\text { effectiveness }\end{array}$ & $\begin{array}{l}\text { - Not supporting } \\
\text { the AR and MR } \\
\text { combination }\end{array}$ \\
\hline Lin, Yu [23] & $\begin{array}{l}\text { Wearable spherical } \\
\text { video-based virtual } \\
\text { reality }\end{array}$ & $\frac{v}{v}$ & $\begin{array}{l}\text { Novelty } \\
\text { Enhance learning } \\
\text { and teaching }\end{array}$ & $\begin{array}{ll}\text { - } & \text { Low time } \\
\text { efficiency } \\
\text { - } \quad \text { Low performance } \\
\text { effectiveness }\end{array}$ \\
\hline
\end{tabular}

\section{Proposed Method}

This section shows how to improve the learning process based on new educational models. The proposed new learning method is based on the IoT in e-learning. As a result, the following hypothesis is put forth:

Hypothesis 1. The IoT-based e-learning has a considerable impact on flexibility.

Hypothesis 2. The IoT-based e-learning has a substantial influence on the learning experience.

Hypothesis 3. The IoT-based e-learning has a significant effect on educational productivity.

Hypothesis 4. The IoT-based e-learning has a significant effect on the quality of education.

\subsection{Problem Statement}

The e-learning system allows students to complete their classes on their devices such as tablets, smartphones, laptops, etc. They will also be able to attend classes online and whole participatory learning [24].

Implementing the IoT as a new factor in e-learning can facilitate interaction between students and teachers and objects (devices). This interaction means that devices can communicate with each other and with people.

\subsection{IoT e-Learning}

Due to the high efficiency of the IoT in education, students enjoy many benefits. This technology allows them to use all models of education, including personal, dynamic, and participatory. In addition, interacting with many objects connected to the web, students access unlimited resources at any location and time and receive content beyond the classroom. Universities can use the IoT in automation, energy management, research experiments, etc., for their members [25]. The general idea of using the IoT in e-learning is to create an environment for acquiring knowledge in a modern and efficient way according to the needs of students. The IoT has many advantages in e-learning, including:

$\checkmark \quad$ Existence of intelligent interactive class.

$\checkmark \quad$ Increase students' creativity by using updated tools.

$\checkmark$ Comprehensive reporting of student activities.

The IoT allows teachers to improve their performance in the online learning environment. This technology supports the classroom by improving teaching methods and processes, increasing teaching resources, and saving costs. Learning resources on devices, such as digital books, are much more interactive. It is worth noting that there is a constant need for up-to-date technologies in educational activities, such as high-speed wireless networks or adequate bandwidth for sharing audio and video files [26].

IoT devices in the proposed model communicate with each other or with other students' devices, and any device can request training information. To gain user control over online class transactions, a common key is assigned to devices by the BC-based model [27]. 
This system checks the owner and distributes the shared key on the devices. IoT devices communicate without any central reference if the key is valid, and centralized architecture becomes meaningless [28].

Blockchain (BC) provides a platform for IoT-connected devices to manage protected data. The main strengths of using BC alongside IoT are:

- Reduce costs by communicating directly and without intermediaries with the customer.

- Reduce the risk of accidents by providing trust between IoT devices.

* Accelerate real-time transactions.

A combination of IoT with educational content can develop students' skills in the fastest method. The IoT is employed in the core learning process, including listening to courses, taking notes, and writing, to guide students to use resources for amusement and extracurricular communication actively. Sensors exist on everyday items and have their own data transmission channels, storage, and applications. They constitute a vast sensor network that enables the IoT to monitor and safeguard people through objects. Based on the information obtained from the nodes, teachers might develop an interactive website utilizing network infrastructure and educational ideas. Students have the chance to select and download their course at any time and place according to the progress of learning to best implement personalized learning. During the online test, professors design and submit numerous test questions, and students can choose the test questions according to their level of expertise. The IoT-based interactive class seems to bring higher satisfaction to learners.

The IoT does a lot to increase students' creativity, using mobile phones, smartwatches, tablets, and other connected devices to generate and express ideas instead of the traditional, simple methods of the past. In the age of massive information, it forces the mind to be creative so as not to ignore much of the existing data and turn the formerly trivial content into valid and original data and information. This has led to a dramatic increase in creativity in new education systems in which technologies have become prevalent.

A student's academic achievement, including grades, is included in the student performance report in the traditional education system, and the performance score is not considered to be an indicator of their activity-based performance. Furthermore, traditional models are incapable of determining the state of each student throughout numerous activities in the learning environment.

Student performance may be evaluated automatically with the advent of the IoT, which can find temporal and geographical trends and deliver critical information to teachers and parents continually. The data included in the active nodes of the learning environment is used to generate the required patterns. It has also been suggested that a cloud-based storage mechanism be implemented to administrate IoT-based activity data properly.

\subsection{IoT for Examinations}

According to the properties of the IoT world, which applies both the one-to-many and the multi-to-multi communication models, all items in our surroundings are connected and generate new signals every second. Local things can also communicate with other virtual or real objects through an inter-network architecture compatible with the Internet. The term "real time" refers to the fact that students can live in a real-time environment from 7 a.m. to 12 p.m., seven days a week, and access primary educational and technical data or information.

This IoT architecture model provides an increased chance to deploy other intelligent devices such as drivers, networks, and servers that can receive IP addresses and cloud infrastructure, which allows for the processing of large volumes of data and surveys much more quickly than previously possible. The smart devices in this design, which have a variety of capabilities for observation, monitoring, communication, and decision making, have the potential to revolutionize the training and evaluation model completely.

During the tests, the data sent from the sensor nodes are examined and processed to detect anomalies. The teacher receives data that identifies which students are misbehaving 
to send cheating alerts to these suspicious students or remove them from the exam. Figure 2 shows the proposed model for e-learning on the IoT. All the steps of forming a class and holding an exam take place within this framework.

A collection of IoT devices, including cameras, microphones, and wearables, collects data from students in real time, which is then stored and analyzed. Wireless technology such as Bluetooth, ZigBee, and other similar protocols is used for the transmission of data from sensors to receiving devices. The IoT hub links student gadgets to cloud storage, which allows for the storing and processing of data on a larger scale. The collected data are processed in real time in the cloud using machine learning (ML) algorithms, allowing faster decision making. The teacher obtains the outcomes on their unique profile and adjusts their educational approach during teaching or exams.

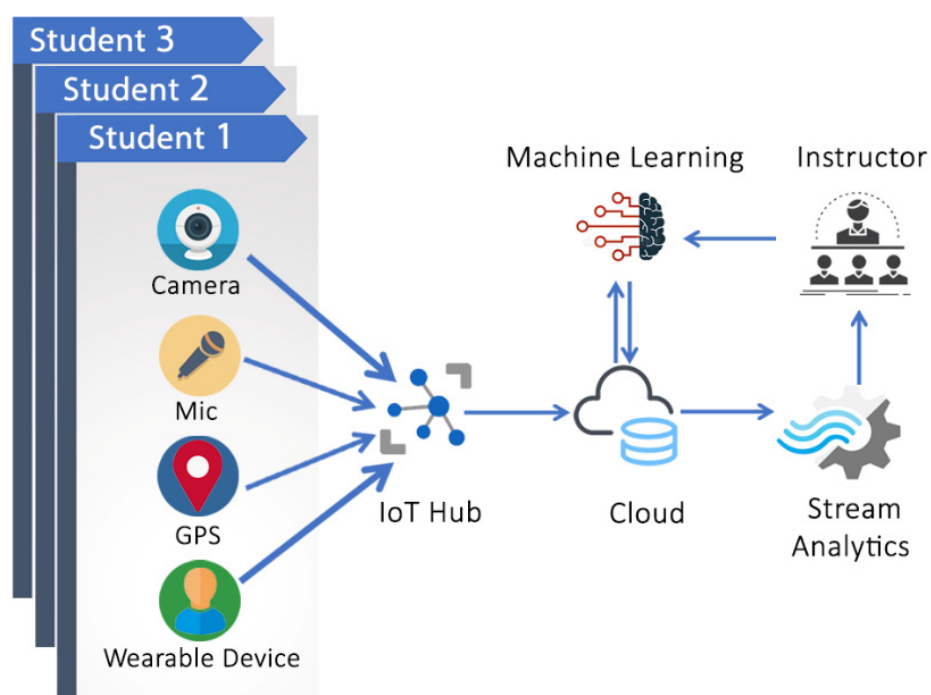

Figure 2. IoT-based model for e-learning.

Monitoring online exams is very difficult because students are not in a centralized location, and there are different ways to cheat on online exams compared with face-to-face exams. Platforms have been designed in which online observers use webcams to monitor student behavior. Where observers watch several webcams, but unfortunately, there is no tool to record the parameters of other individuals taking part in the tests.

Cheating online exams is usually only easy with the help of someone who is stationed somewhere in the room to answer online questions. Today, of course, the use of 360-degree cameras is common, but there are no recorded results that prove the effectiveness of these cameras. New models must be used to address this vital weakness and increase confidence in online testing. The most critical of these is the collection of important data from the student along with webcam data, such as electro encephalo gram (EEG), electro cardiogram (ECG), skin resistance, and performance analysis. For example, how does a student react when a difficult question arises? This type of data can be easily obtained by closely monitoring these sensors. Accordingly, it can be used to analyze whether the student is cheating or has cheated before.

ML has been utilized in various activities, including monitoring systems during teaching and exam periods, in a variety of situations. A sophisticated e-learning process can benefit from ML, which provides powerful tools for ongoing quality improvement. In the course of an exam or real-time teaching process, the proposed ML model is employed to detect an uncommon event. It is predicted that it will assist teachers and supervisors in improving decision making and preventing online learning errors.

Clustering is employed in this design as one of the standard machine learning approaches that may be performed without supervision and is used to group data points. It is a widely well-known technique in the field of statistical analysis. Clustering is a technique 
for organizing data points into groups based on each data point's traits and attributes. Clustering is used with a specific data set to organize data points into groups [29].

The $\mathrm{K}$ means algorithm is one of the most extensively used clustering algorithms, and it is also utilized in this design to allocate a group to unlabeled data. Every group is determined by computing the distance between a data point and the core of the group, and each data point is allocated to one of the groups defined in this way [30]. This technique is rapid and scalable, and its primary application is the identification and analysis of anomalies [31].

\subsection{Data Collection}

Students' online questionnaire information was collected from April 2021 to June 2021. Three IoT and e-learning experts performed the pre-test. Table 2 shows the characteristics of the people participating in the survey separately.

Table 2. Respondents' details.

\begin{tabular}{cccc}
\hline Attributes & Property & Value & Percentage (\%) \\
\hline \multirow{2}{*}{ Gender } & Male & 191 & 68.21 \\
\cline { 2 - 4 } & Female & 89 & 31.79 \\
\cline { 2 - 4 } Age & $<23$ & 50 & 17.85 \\
\cline { 2 - 4 } & $23-29$ & 102 & 36.42 \\
\cline { 2 - 4 } & $29-35$ & 85 & 30.35 \\
\hline \multirow{2}{*}{ Education rate } & $>35$ & 43 & 15.35 \\
\cline { 2 - 4 } & Undergraduate & 104 & 37.14 \\
\cline { 2 - 4 } & Graduate & 176 & 62.86 \\
\hline
\end{tabular}

According to Table 3, the survey was measured on a Likert scale from 1 (completely disagree) to 5 (completely agree). Out of 600 surveys submitted for students, 280 responses were returned, of which 263 were helpful, so the sample size $(43.8 \%)$ is acceptable.

Table 3. Measurement instruments.

\begin{tabular}{|c|c|c|c|}
\hline Variables & & Items & Scale \\
\hline \multirow{3}{*}{ Flexibility } & $\mathrm{F} 1$ & $\begin{array}{l}\text { The IoT-based e-learning } \\
\text { allows me to organize my } \\
\text { teaching time. }\end{array}$ & \multirow{6}{*}{$\begin{array}{c}1 \text { (Completely disagree) } \\
2 \text { (Disagree) } \\
3 \text { (No comment) } \\
4 \text { (Agree) } \\
5 \text { (Completely agree) }\end{array}$} \\
\hline & F2 & $\begin{array}{l}\text { The IoT-based e-learning } \\
\text { allows me to have complete } \\
\text { control over my education. }\end{array}$ & \\
\hline & F3 & $\begin{array}{l}\text { My learning environment is } \\
\text { flexible. }\end{array}$ & \\
\hline \multirow{3}{*}{$\begin{array}{l}\text { Learning } \\
\text { experience }\end{array}$} & LE1 & $\begin{array}{l}\text { A teacher has trained me to } \\
\text { learn remotely. }\end{array}$ & \\
\hline & LE2 & $\begin{array}{l}\text { I have been trained in effective } \\
\text { e-learning. }\end{array}$ & \\
\hline & LE3 & $\begin{array}{l}\text { Students are happy to be } \\
\text { taught with this model. }\end{array}$ & \\
\hline
\end{tabular}


Table 3. Cont.

\begin{tabular}{|c|c|c|c|}
\hline Variables & & Items & Scale \\
\hline \multirow{6}{*}{$\begin{array}{l}\text { Educational } \\
\text { productivity }\end{array}$} & EP1 & I am an effective student. & \\
\hline & EP2 & $\begin{array}{l}\text { I am satisfied with the quality } \\
\text { of our IoT-based e-learning. }\end{array}$ & \\
\hline & EP3 & I train efficiently. & \\
\hline & EP4 & I am a very active student. & \\
\hline & EP5 & $\begin{array}{l}\text { My teacher believes that I am } \\
\text { an active student. }\end{array}$ & \\
\hline & EP6 & $\begin{array}{l}\text { Among the students in the } \\
\text { class, I rank my performance in } \\
\text { the upper half of the course. }\end{array}$ & \\
\hline \multirow{3}{*}{ E-learning } & DL1 & $\begin{array}{l}\text { Do a lot of homework daily } \\
\text { during IoT-based e-learning. }\end{array}$ & \\
\hline & DL2 & $\begin{array}{l}\text { IoT-based e-learning allows me } \\
\text { to be more effective. }\end{array}$ & \\
\hline & DL3 & $\begin{array}{l}\text { IoT-based e-learning is an } \\
\text { efficient model for education. }\end{array}$ & \\
\hline \multirow{4}{*}{$\begin{array}{l}\text { Quality of } \\
\text { education }\end{array}$} & QoE1 & $\begin{array}{c}\text { I am satisfied with the } \\
\text { educational opportunities } \\
\text { available at the IoT-based } \\
\text { e-learning. }\end{array}$ & \\
\hline & QoE2 & $\begin{array}{l}\text { My learning time is } \\
\text { commensurate with my living } \\
\text { conditions. }\end{array}$ & \\
\hline & QoE3 & $\begin{array}{l}\text { My learning environment is } \\
\text { stable. }\end{array}$ & \\
\hline & QoE4 & $\begin{array}{l}\text { When I am learning, I forget } \\
\text { what is happening around me. }\end{array}$ & \\
\hline
\end{tabular}

\section{Performance Assessment}

According to the available values, the structures are in a state of reliability. Therefore, internal compatibility is approved. In addition, by examining the mean of variance, the validity of the instrument was also proved. Given the values in Table 4, the AVE results, in which all variables have an AVE value above 0.50, are acceptable. If the variance inflation factor (VIF) is 3.0 or lower, it is impossible for multiple lines to be threatening [32]. Of course, the appropriate VIF standard was assumed to be 5.0 in previous work, but recent studies show that this level is considered very high.

Table 5 shows the discriminant validity as part of the testing process. Discriminant validity was performed to validate how a latent research variable is independent of other items. Discriminant validity is ideal when the mean variance of an individual latent structure has a tremendous amount of multiple square correlations compared with other structures [33]. The results indicate that all the variables under study have discriminant validity values.

The small sample size used in this study is a significant drawback of the design. Although there were just a few respondents, useful identifying information was obtained despite many individuals. Based on quantitative analysis, it has been demonstrated that items connected to online education can be quantified in a reasonable and trustworthy manner. The proposed approach has the potential to be utilized to collect essential information that can be transferred to online learning environments. 
Table 4. Constructs and convergent validity.

\begin{tabular}{|c|c|c|c|c|c|c|}
\hline Constructs & Items & $\lambda$ & VIF & AVE & CR & $\mathrm{CA}$ \\
\hline \multirow{3}{*}{ Flexibility (F) } & F1 & 0.903 & 2.141 & \multirow{3}{*}{0.537} & \multirow{3}{*}{0.814} & \multirow{3}{*}{0.729} \\
\hline & F2 & 0.899 & 1.897 & & & \\
\hline & F3 & 0.871 & 2.019 & & & \\
\hline \multirow{3}{*}{$\begin{array}{l}\text { Learning experience } \\
\text { (LE) }\end{array}$} & LE1 & 0.834 & 1.513 & \multirow{3}{*}{0.585} & \multirow{3}{*}{0.736} & \multirow{3}{*}{0.723} \\
\hline & LE2 & 0.752 & 1.631 & & & \\
\hline & LE3 & 0.834 & 1.207 & & & \\
\hline \multirow{6}{*}{$\begin{array}{c}\text { Educational } \\
\text { productivity (EP) }\end{array}$} & EP1 & 0.876 & 1.403 & \multirow{6}{*}{0.707} & \multirow{6}{*}{0.839} & \multirow{6}{*}{0.724} \\
\hline & EP2 & 0.722 & 2.081 & & & \\
\hline & EP3 & 0.885 & 1.742 & & & \\
\hline & EP4 & 0.783 & 1.859 & & & \\
\hline & EP5 & 0.798 & 1.727 & & & \\
\hline & EP6 & 0.831 & 1.696 & & & \\
\hline \multirow{3}{*}{ E-learning (EL) } & EL1 & 0.733 & 1.551 & \multirow{3}{*}{0.677} & \multirow{3}{*}{0.814} & \multirow{3}{*}{0.762} \\
\hline & EL2 & 0.917 & 1.024 & & & \\
\hline & EL3 & 0.845 & 1.857 & & & \\
\hline \multirow{4}{*}{$\begin{array}{l}\text { Quality of education } \\
\text { (QoE) }\end{array}$} & QoE1 & 0.873 & 1.438 & \multirow{4}{*}{0.633} & \multirow{4}{*}{0.805} & \multirow{4}{*}{0.712} \\
\hline & QoE2 & 0.892 & 1.207 & & & \\
\hline & QoE3 & 0.811 & 1.376 & & & \\
\hline & QoE4 & 0.837 & 1.484 & & & \\
\hline
\end{tabular}

Table 5. Discriminant validity.

\begin{tabular}{cccccc}
\hline & F & LE & EP & EL & QoE \\
\hline Flexibility & 0.735 & & & & \\
\hline Learning experience & 0.592 & 0.747 & & & \\
\hline $\begin{array}{c}\text { Educational } \\
\text { productivity }\end{array}$ & 0.504 & 0.539 & 0.711 & & \\
\hline E-learning & 0.396 & 0.461 & 0.595 & 0.741 & \\
\hline Quality of education & 0.407 & 0.363 & 0.505 & 0.589 & 0.847 \\
\hline
\end{tabular}

Figure 3 compares the views of 200 professors who have used the IoT world with devices connected in the classroom to those who have never experienced it. The professors were confronted with a complete review of the underlying reasons because there were so many various sectors of online education to consider. The findings indicate that teamwork and reflection are the weakest conceivable areas in IoT-based online education, while motivation and interactivity are the most effective. These areas are obvious focal points that should be considered in discussions about expansion and development, as well as educational policy and planning.

The results in Figure 4 clearly show that the score of each section has a significant relationship with the work experience of professors. Younger professors have a more positive outlook than older professors.

Following that, development and expansion plans and other resources can be developed from the results. By examining qualitative findings, we can broaden our understanding of online teacher education conceptualizations. The findings of this combined study can be used to better understand the relationship between faculty online teaching 
and student outcomes, as well as to identify significant topics for future research and policy development.

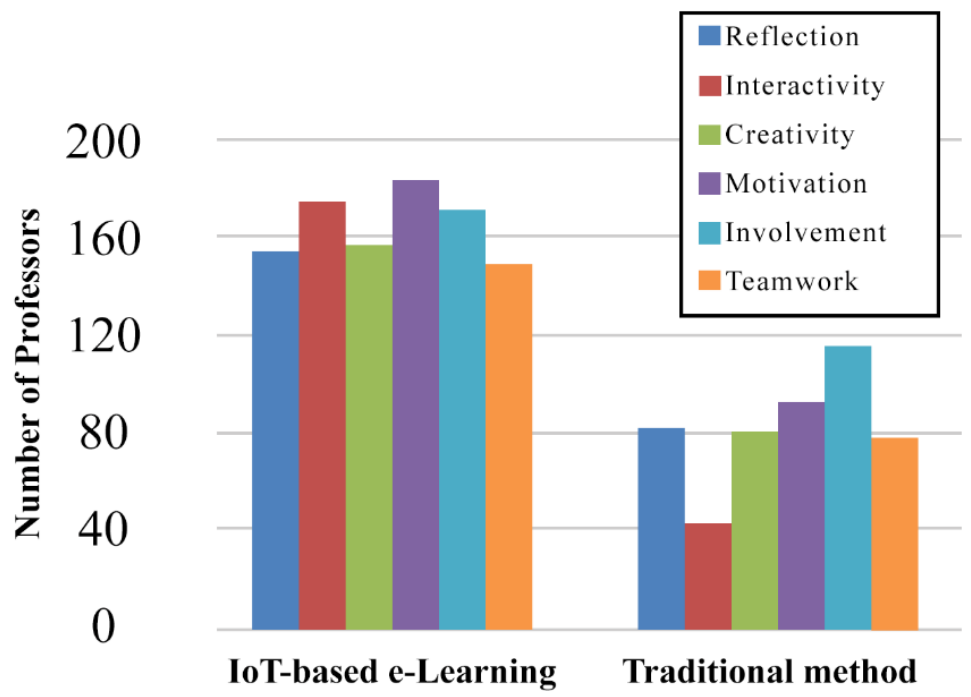

Figure 3. Comparison of traditional method with IoT-based model.

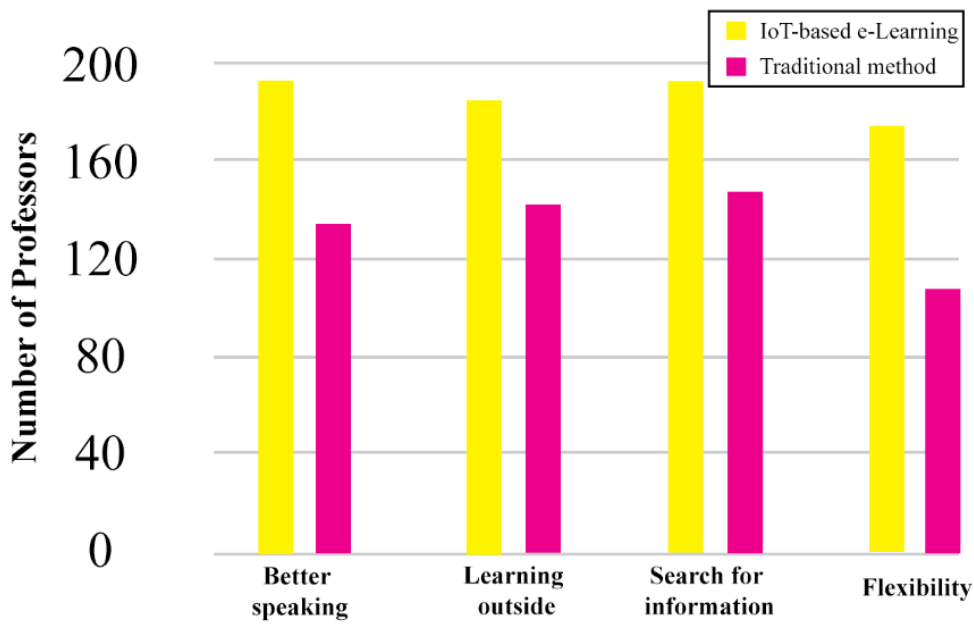

Figure 4. The superiority of IoT-based e-learning.

\section{Conclusions and Future Work}

In a brief period, the social constraints of the COVID-19 pandemic led to significant changes in the way students and faculty taught, communicated, and collaborated. This article provides an integrated IoT framework for e-learning in undergraduate and graduate education. A modern framework for developing educational approaches in smart classrooms and expanding the concept of collaborative learning through the IoT has been introduced. Based on the accurate information received, this framework selects the most appropriate educational materials and reduces the possibility of cheating during the exam. In addition, the proposed IoT-based e-learning method has many effects on learners' level of knowledge and cognitive burden. Thus, one of the most significant consequences of IoT-based e-learning settings is that the typical responsibilities of students and teachers are fundamentally changed. Because real and virtual items are linked together, students and teachers can interact practically anywhere, at any time, and can participate in scientific projects, assignments, and research. The IoT-based e-learning system's key advantages are its high levels of flexibility, accessibility, adaptability, and scalability. Despite the problems it faces, the system can potentially transform the e-learning model soon. The results clearly show that there is a significant relationship between distance education and all variables 
studied. By analyzing the variables and their impact on distance education, it can be concluded that a modern and efficient education system can be created by creating the appropriate infrastructure.

VR training models are confronted with a variety of difficulties, including hardware issues. On the other hand, this paradigm brings about a shift in education through the use of novel educational procedures and methodologies. For the future, by using dynamic teaching methods and the integration of technology in education, it is possible to make learning content more appropriate while also providing students with a more comprehensive learning experience. Educational content can be combined with VR to develop a more effective educational environment. Furthermore, it is recommended to create an intelligent student authentication system based on IoT tools, which will improve e-learning.

Author Contributions: Conceptualization, A.M.R., R.A.N., M.H.M., T.S.M., M.S., M.H. and A.A.-M.; Data curation, A.M.R., R.A.N., M.H.M., T.S.M., M.S., M.H. and A.A.-M.; Formal analysis, A.M.R., R.A.N., M.H.M., T.S.M., M.S., M.H. and A.A.-M.; Investigation, A.M.R., M.H.M., T.S.M., M.S., M.H. and A.A.-M.; Methodology, A.M.R., R.A.N., T.S.M., M.S., M.H. and A.A.-M.; Project administration, A.M.R., R.A.N.; Resources, A.M.R., R.A.N., M.H.M., M.S., M.H. and A.A.-M.; Software, A.M.R., R.A.N., M.H.M., T.S.M., M.S. and A.A.-M.; Supervision, R.A.N., M.H.M., T.S.M., M.S., M.H. and A.A.M. Validation, A.M.R., R.A.N., M.H.M., M.S. and M.H.; Visualization, and Writing-original draft, A.M.R., M.S., M.H. and A.A.-M.; Writing-review \& editing, R.A.N., T.S.M. and M.S. All authors have read and agreed to the published version of the manuscript.

Funding: This research is not supported.

Institutional Review Board Statement: Not applicable.

Informed Consent Statement: Not applicable.

Data Availability Statement: Not applicable.

Conflicts of Interest: We declare that this manuscript is original, has not been published before and is not currently being considered for publication elsewhere.

\section{References}

1. Fu, Y.; Zhang, C.; Chen, Y.; Gu, F.; Baležentis, T.; Streimikiene, D. Ordered weighted logarithmic averaging distance-based pattern recognition for the recommendation of traditional Chinese medicine against COVID-19 under a complex environment. Kybernetes 2021. [CrossRef]

2. Galanakis, C.M. The food systems in the era of the Coronavirus (COVID-19) pandemic crisis. Foods 2020, 9, 523. [CrossRef]

3. Hidalgo, G.I.; Sánchez-Carracedo, F.; Romero-Portillo, D. COVID-19 Emergency remote teaching opinions and academic performance of undergraduate students: Analysis of 4 students' profiles: A case study. Mathematics 2021, 9, 2147. [CrossRef]

4. Gardas, B.B.; Navimipour, N.J. Performance evaluation of higher education system amid COVID-19: A threat or an opportunity? Kybernetes 2021. [CrossRef]

5. Kausar, S.; Huahu, X.; Ullah, A.; Wenhao, Z.; Shabir, M.Y. Fog-assisted secure data exchange for examination and testing in E-learning system. Mob. Netw. Appl. 2020, 1-17. [CrossRef]

6. Furini, M.; Galli, G.; Martini, M.C. An online education system to produce and distribute video lectures. Mob. Netw. Appl. 2019, 25, 969-976. [CrossRef]

7. Bekesiene, S.; Vasiliauskas, A.; Hošková-Mayerová, Š.; Vasilienè-Vasiliauskienè, V. Comprehensive assessment of distance learning modules by fuzzy AHP-TOPSIS method. Mathematics 2021, 9, 409. [CrossRef]

8. Fadda, E.; Perboli, G.; Tadei, R. Customized multi-period stochastic assignment problem for social engagement and opportunistic IoT. Comput. Oper. Res. 2018, 93, 41-50. [CrossRef]

9. Sadrishojaei, M.; Navimipour, N.J.; Reshadi, M.; Hosseinzadeh, M. A new preventive routing method based on clustering and location prediction in the mobile Internet of things. IEEE Internet Things J. 2021, 8, 10652-10664. [CrossRef]

10. Sadrishojaei, M.; Navimipour, N.J.; Reshadi, M.; Hosseinzadeh, M. Clustered routing method in the Internet of things using a moth-flame optimization algorithm. Int. J. Commun. Syst. 2021, 34, e4964. [CrossRef]

11. Sadrishojaei, M.; Navimipour, N.J.; Reshadi, M.; Hosseinzadeh, M. A new clustering-based routing method in the mobile internet of things using a krill herd algorithm. Clust. Comput. 2021, 1-11. [CrossRef]

12. Sadrishojaei, M.; Navimipour, N.J.; Reshadi, M.; Hosseinzadeh, M.; Unal, M. An energy-aware clustering method in the IoT using a swarm-based algorithm. Wirel. Netw. 2021, 1-12. [CrossRef]

13. Alhasan, A.; Audah, L.; Ibrahim, I.; Al-Sharaa, A.; Al-Ogaili, A.S.; Mohammed, J.M. A case-study to examine doctors' intentions to use IoT healthcare devices in Iraq during COVID-19 pandemic. Int. J. Pervasive Comput. Commun. 2020. [CrossRef] 
14. Amasha, M.A.; Areed, M.F.; Alkhalaf, S.; Abougalala, R.A.; Elatawy, S.M.; Khairy, D. The future of using Internet of things (loTs) and context-aware technology in E-learning. In Proceedings of the 9th International Conference on Educational and Information Technology, Oxford, UK, 11-13 February 2020.

15. Zaharov, A.A.; Nissenbaum, O.V.; Ponomarov, K.Y.; Shirokih, A.V. Use of open-source Internet of things platform in education projects. In Proceedings of the 2018 Global Smart Industry Conference (GloSIC), Chelyabinsk, Russia, 13-15 November 2018; pp. 1-6.

16. Mohamed, F.; Abdeslam, J.; Lahcen, E.B. Towards new approach to enhance learning based on Internet of things and virtual reality. In Proceedings of the International Conference on Big Data and Internet of Thing-BDIOT2017, Beijing, China, 24-26 October 2018; p. 54.

17. Yang, Y.; Yu, K. Construction of distance education classroom in architecture specialty based on internet of things technology. Int. J. Emerg. Technol. Learn. 2016, 11, 56-61. [CrossRef]

18. Vharkute, M.; Wagh, S. An architectural approach of internet of things in E-Learning. In Proceedings of the 2015 International Conference on Communications and Signal Processing (ICCSP), Chengdu, China, 10-11 October 2015; pp. $1773-1776$.

19. Cornel, C.-E. The role of internet of things for a continuous improvement in education. Hyperion Econ. J. $2015,2,24-31$.

20. Abbasy, M.B.; Quesada, E.V. Predictable Influence of IoT (Internet of Things) in the higher education. Int. J. Inf. Educ. Technol. 2017, 7, 914-920. [CrossRef]

21. Zahedi, M.H.; Dehghan, Z. Effective E-learning utilizing Internet of things. In Proceedings of the 13th Iranian and 7th National Conference on e-Learning and e-Teaching (ICeLeT), Tehran, Iran, 20-21 February 2019; pp. 1-6.

22. Ying, L.; Jiong, Z.; Wei, S.; Jingchun, W.; Xiaopeng, G. VREX: Virtual reality education expansion could help to improve the class experience (VREX platform and community for VR based education). In Proceedings of the IEEE Frontiers in Education Conference (FIE), Indianapolis, IN, USA, 18-21 October 2017; pp. 1-5.

23. Lin, H.C.-S.; Yu, S.-J.; Sun, J.C.-Y.; Jong, M.S.Y. Engaging university students in a library guide through wearable spherical video-based virtual reality: Effects on situational interest and cognitive load. Interact. Learn. Environ. 2019, 1-16. [CrossRef]

24. Chicharro, F.I.; Giménez, E.; Sarría, I. The enhancement of academic performance in online environments. Mathematics 2019, 7, 1219. [CrossRef]

25. Elyamany, H.F.; AlKhairi, A.H. IoT-academia architecture: A profound approach. In Proceedings of the IEEE/ACIS 16th International Conference on Software Engineering, Artificial Intelligence, Networking and Parallel/Distributed Computing (SNPD), Takamatsu, Japan, 1-3 June 2015.

26. Aldowah, H.; Rehman, S.U.; Ghazal, S.; Umar, I. Internet of things in higher education: A study on future learning. J. Phys. Conf. Ser. 2017, 892, 012017. [CrossRef]

27. Chen, G.; Xu, B.; Lu, M.; Chen, N.-S. Exploring blockchain technology and its potential applications for education. Smart Learn. Environ. 2018, 5, 1. [CrossRef]

28. Dorri, A.; Kanhere, S.S.; Jurdak, R. Blockchain in internet of things: Challenges and solutions. arXiv 2016, arXiv:1608.05187.

29. Khalid, S.; Hwang, H.; Kim, H.S. Real-world data-driven machine-learning-based optimal sensor selection approach for equipment fault detection in a thermal power plant. Mathematics 2021, 9, 2814. [CrossRef]

30. Reyes-Campos, J.; Alor-Hernández, G.; Machorro-Cano, I.; Olmedo-Aguirre, J.; Sánchez-Cervantes, J.; Rodríguez-Mazahua, L. Discovery of resident behavior patterns using machine learning techniques and IoT paradigm. Mathematics 2021, 9, 219. [CrossRef]

31. Clark, A.Y.; Blumenfeld, N.; Lal, E.; Darbari, S.; Northwood, S.; Wadpey, A. Using K-means cluster analysis and decision trees to highlight significant factors leading to homelessness. Mathematics 2021, 9, 2045. [CrossRef]

32. Olague, H.M.; Etzkorn, L.H.; Gholston, S.; Quattlebaum, S. Empirical validation of three software metrics suites to predict fault-proneness of object-oriented classes developed using highly iterative or agile software development processes. IEEE Trans. Softw. Eng. 2007, 33, 402-419. [CrossRef]

33. Al-Okaily, M.; Alqudah, H.; Matar, A.; Lutfi, A.; Taamneh, A. Dataset on the acceptance of E-learning system among universities students' under the COVID-19 pandemic conditions. Data Brief. 2020, 32, 106176. [CrossRef] [PubMed] 